\title{
Respiratory syncytial virus, human metapneumovirus, and influenza virus infection in Bangkok, 2016-2017
}

\author{
Ilada Thongpan ${ }^{1}$, Nungruthai Suntronwong ${ }^{1}$, Preeyaporn Vichaiwattana ${ }^{1}$, Nasamon Wanlapakorn ${ }^{1}$, Sompong \\ Vongpunsawad $^{1}$, Yong Poovorawan ${ }^{\text {Corresp. } 1}$ \\ ${ }^{1}$ Center of Excellence in Clinical Virology, Department of Pediatrics, Faculty of Medicine, Chulalongkorn University, Bangkok, Thailand \\ Corresponding Author: Yong Poovorawan \\ Email address: Yong.P@chula.ac.th
}

Children and adults residing in densely populated urban centers around the world are at risk of seasonal influenza-like illness caused by respiratory viruses such as influenza virus, human metapneumovirus (hMPV), and respiratory syncytial virus (RSV). In a large metropolitan of Thailand's capital city Bangkok, most respiratory infections are rarely confirmed by molecular diagnostics. We therefore examined the frequency of RSV, hMPV, and influenza virus in 8,842 patients who presented influenza-like illness and sought medical care at a large hospital in Bangkok between 2016 and 2017. Using a multiplex real-time reverse-transcription polymerase chain reaction (RT-PCR), 30.5\% $(2,699 / 8,842)$ of nasopharyngeal (NP) swab samples tested positive for one or more of these viruses. Influenza virus comprised $17.3 \%(1,528 / 8,842)$, of which the majority were influenza A/H3N2. Such infection was most prevalent among adults and the elderly. RSV was identified in $11.4 \%(1,011 / 8,842)$ and were mostly ON1 and BA9 genotypes. Of the hMPVpositive samples $(3.6 \%, 318 / 8,842)$, genotypes $A 2, B 1$, and $B 2$ were detected. A small number of individuals experienced co-infections $(1.8 \%, 155 / 8,842)$, most commonly between RSV and influenza A/H3N2. RSV and hMPV co-infections were also found, but mainly in young children. Viral respiratory tract infection peaked locally in the rainy season (June to September). These findings support the utility of rapid nucleic acid testing of RSV, hMPV, and influenza virus in patients with ILI. 
1 Respiratory syncytial virus, human metapneumovirus, and influenza virus

\section{2 infection in Bangkok, 2016-2017}

3 Ilada Thongpan ${ }^{1}$, Nungruthai Suntronwong ${ }^{1}$, Preeyaporn Vichaiwattana ${ }^{1}$, Nasamon

4 Wanlapakorn $^{1}$, Sompong Vongpunsawad ${ }^{1}$ and Yong Poovorawan ${ }^{1}$

5

$6{ }^{1}$ Center of Excellence in Clinical Virology, Department of Pediatrics, Faculty of Medicine,

7 Chulalongkorn University, Bangkok, Thailand

8

9

10

11

12

13

14

15

16 Corresponding author:

17 Yong Poovorawan, yong.p@chula.ac.th 


\section{ABSTRACT}

Children and adults residing in densely populated urban centers around the world are at risk of seasonal influenza-like illness (ILI) caused by respiratory viruses such as influenza virus, human metapneumovirus (hMPV), and respiratory syncytial virus (RSV). In a large metropolitan of Thailand's capital city Bangkok, most respiratory infections are rarely confirmed by molecular diagnostics. We, therefore, examined the frequency of RSV, hMPV, and influenza virus in 8,842 patients who presented with ILI and sought medical care at a large hospital in Bangkok between 2016 and 2017. Using a multiplex real-time reverse-transcription polymerase chain reaction (RT-PCR), 30.5\% $(2,699 / 8,842)$ of nasopharyngeal (NP) swab samples tested positive for one or more of these viruses. Influenza virus comprised $17.3 \%(1,528 / 8,842)$, of which the majority were influenza A/H3N2. Such infection was most prevalent among adults and the elderly. RSV was identified in $11.4 \%(1,011 / 8,842)$ and were mostly ON1 and BA9 genotypes. Of the hMPV-positive samples $(3.6 \%, 318 / 8,842)$, genotypes A2, B1, and B2 were detected. Among samples tested positive for more than one virus, RSV was co-detected mainly with influenza $\mathrm{A} / \mathrm{H} 3 \mathrm{~N} 2$, while RSV and hMPV co-infections were found mainly in young children. Viral respiratory tract infection peaked locally in the rainy season (June to September). These findings support the utility of rapid nucleic acid testing of RSV, hMPV, and influenza virus in patients with ILI. 
38

39

40

41

42

\section{INTRODUCTION}

Respiratory tract infection is a major contributor to morbidity and mortality among children and adults worldwide (Boloursaz et al., 2013; Garg et al., 2015). Most recognized is the seasonal influenza virus infection, which is responsible for about 290,000 to 650,000 deaths each year $(W H O, 2018)$. Epidemiological studies have shown that infants, young children, and the elderly are especially at risk of infection by both subtypes of RSV (designated A and B) (Henrickson et al., 2004). Even hMPV is now recognized as a frequent cause of acute respiratory tract infections in children predominantly $\leq 5$ years of age, elderly adults, and immunocompromised patients (Johnstone et al., 2008; Williams et al., 2004). Each of the two genetically and antigenically distinct groups of hMPV (A and B) can be further divided into genetic subgroups 1 and 2 (Boivin et al., 2002).

Multiple groups of different respiratory viruses frequently co-circulate with a variable pattern of predominance in Thailand. Data on the prevalence of infection caused by these viruses are often incomplete and limited due to their similar clinical presentation and seasonality overlap (Thanasugarn et al., 2003; Horthongkham et al., 2014). The systematic use of molecular diagnostics such as the real-time reverse transcription-polymerase chain reaction (RTPCR) assay has been important in improving accurate diagnosis of viral respiratory infections and has proven extremely useful for disease surveillance (Mahony et al., 2008).

Here, we aimed to assess the disease burden caused by RSV, hMPV, and influenza virus in a large patient population of all ages who presented influenza-like illness (ILI) and sought medical care at a hospital in Bangkok within the past two years. 
60

61

62

63

64

65

66

67

\section{MATERIALS AND METHODS}

\section{Study design and specimens}

We retrospectively tested 8,842 stored respiratory samples obtained from both in-patient and out-patient individuals of all ages with ILI who sought medical care at Bangpakok 9 International Hospital in Bangkok and collected consecutively between January 2016 and December 2017 . ILI was defined as fever $\left(>38^{\circ} \mathrm{C}\right)$ and accompanying respiratory symptoms such as cough, sore throat, or pharyngitis. This study analyzed de-identified convenient samples and extended an earlier investigation of an ongoing influenza virus prevalence in Thailand (Suntronwong et al., 2017). Available patient information included gender and age, but not extensive clinical information nor disease severity. The Institutional Review Board of the Faculty of Medicine of Chulalongkorn University approved this study (IRB number 609/59).

\section{Real-time RT-PCR}

RNA was extracted from $200 \mu \mathrm{L}$ of specimens using the Viral Nucleic Acid Extraction Kit (RBC Bioscience, Taiwan, R.O.C.) according to the manufacturer's instructions. RSV and hMPV detections were performed using an in-house TaqMan-based multiplex one-step real-time RT-PCR. The primers and probes targeted the M gene of RSV and the F gene of hMPV (Table 1). The RSV probe was labeled with 6-carboxy-fluorescein (FAM) at the 5' end and Black Hole Quencher-1 (BHQ-1) at the 3' end. The hMPV probe was labeled with 6-carboxy-fluorescein (HEX) at the 5' end and Black Hole Quencher-1 (BHQ-1) at the 3' end. The reaction mixture contained $2 \mu \mathrm{L}$ RNA, $10 \mu \mathrm{mol}$ of each of the primers and probes, and SensiFAST Probe NoROX One-Step reagent (Bioline, London, U.K.). Cycling parameters included 1 cycle for 20 min at $42^{\circ} \mathrm{C}$, initial denaturation for 3 minutes at $95^{\circ} \mathrm{C}, 50$ cycles for 10 seconds at $95^{\circ} \mathrm{C}$ and 20 
83 seconds at $60^{\circ} \mathrm{C}$. This assay has a limit of detection of 100 genome copies per reaction for both

84 viruses. No cross-detections were observed between the two viruses and other respiratory

85 viruses including influenza A and B viruses, adenovirus, enterovirus, rhinovirus, and

86 coronavirus. Real-time RT-PCR assay of influenza A and B viruses was previously described

87 (Suwannakarn et al., 2008). Parallel detection of glyceraldehyde 3-phosphate dehydrogenase

88 (GAPDH) gene served as an internal control. Fluorescence signals cycle threshold (Ct) was

89 based on optimization and values $\leq 38$ were considered positive.

90

\section{Conventional RT-PCR}

Samples tested positive for RSV and/or hMPV were genotyped. Complementary DNA

93

94 was synthesized using the ImProm-II Reverse Transcription System (Promega, Madison, WI) according to the manufacturer's instructions. RNA and random hexamers were incubated at $70^{\circ} \mathrm{C}$ for 5 minutes, followed by extension for 2 hours at $42^{\circ} \mathrm{C}$ and inactivation at $70^{\circ} \mathrm{C}$ for 15 minutes. Amplification of the partial RSV glycoprotein $(\mathrm{G})$ gene inclusive of the second hypervariable region (HVR2) and the F gene was performed using semi-nested RT-PCR as previously described (Auksornkitti et al., 2014). Cycling parameters were initial denaturation at $94^{\circ} \mathrm{C}$ for 3 minutes, 40 cycles of denaturation at $94^{\circ} \mathrm{C}$ for 20 seconds, annealing at $55^{\circ} \mathrm{C}$ for 20 seconds, elongation at $72^{\circ} \mathrm{C}$ for 90 seconds, and a final extension at $72^{\circ} \mathrm{C}$ for 10 minutes. Identical amplification parameters were carried out in the second-round PCR for 30 cycles. Partial F-gene of hMPV was subjected to nested-PCR as previously described (Chung et al., 2008). The PCR conditions were initial denaturation at $95^{\circ} \mathrm{C}$ for 3 minutes, 35 cycles of $95^{\circ} \mathrm{C}$ for 1 minute, $55^{\circ} \mathrm{C}$ for 1 minute, $72^{\circ} \mathrm{C}$ for 1 minute, and a final extension at $72^{\circ} \mathrm{C}$ for 3 minutes. The PCR products for RSV-A (840 bp), RSV-B (720 bp), and hMPV (750 bp) were visualized 
106 using 2\% agarose gel electrophoresis and purified using the GeneAll Expin gel extraction kit

107 (GeneAll Biotechnology, Seoul, Korea) according to the manufacturer's instructions. Purified

108 PCR products were subjected to Sanger sequencing.

109

110

Sequence and phylogenetic analyses of RSV and hMPV genotypes

111

Nucleotide sequences of RSV and hMPV strains were aligned using ClustalW

112

implemented in BioEdit (version 7.0.9) by comparison to the sequences previously assigned to

113 specific genotypes (Table S1 and Table S2). Phylogenetic trees were constructed using the

114 maximum likelihood method implemented in the MEGA6 (Tamura et al., 2013). The reliability

115 of the tree based on the Tamura-Nei model was estimated using 1,000 bootstrap pseudo-

116 replications. Sequences were considered the same genotype if they clustered together with

117 bootstrap values of 70-100\% (Venter et al., 2001).

118 Nucleotide sequences were submitted to the GenBank database under the accession

119 numbers MH447703-MH447725 (RSV-A), MH447726-MH447818 (RSV-B), and MH447819-

120 MH447950 (hMPV).

121

122

\section{Statistical analysis}

The association between virus prevalence and the patient age at infection was assessed

using univariate analyses (SPSS software version 22.0). P-values were calculated using the Chiconsidered statistically significant. 


\section{RESULTS}

129 The overall prevalence of RSV, hMPV, and influenza virus

130 We retrospectively tested 8,842 consecutive respiratory samples $(48.5 \%$ males, age range

$1310-106$ years $)$. Of these, $30.5 \%(2,699 / 8,842)$ were positive for one or more viruses. Influenza

132 virus was most commonly identified $(17.3 \%, 1,528 / 8,842)$, followed by RSV $(11.4 \%$,

133 1,011/8,842) and hMPV (3.6\%, 318/8,842) (Table 2). Influenza virus and RSV were more

134 prevalent in 2016 than in 2017. To facilitate analysis, samples were categorized into seven

135 groups in order to examine the distribution of viral infection relative to age (Table 3 and Table

136 S3). Regardless of gender, the burden of RSV was greatest among children 5 years of age and 137 younger (21.2\% and $15.4 \%$ among those $\leq 2$ and $3-5$ years of age, respectively). Frequency of

138 RSV infection appeared to decrease with increasing age and was $<9 \%$ in those older than 5 years 139 of age $(\mathrm{p}<0.0001)$. In contrast, influenza virus infection was more frequently found among older 140 individuals. Meanwhile, hMPV infection was distributed among all ages (1.7-5.7\%).

\section{Seasonal and genotype distribution of RSV, hMPV, and influenza virus}

The prevalence of viral etiology of influenza-like infection differed slightly among the viruses examined. Among 1,011 RSV-positive samples, subgroup identification was possible for 488 specimens. Of these, $36.3 \%$ (177/488) were RSV-A and 66.4\% (324/488) were RSV-B.

RSV infection appeared most frequently in the rainy months (between July and November) with the highest annual prevalence of 37\% (206/555) and 17.3\% (136/784) in August 2016 and September 2017, respectively (Fig. 1A). Although RSV-A and RSV-B were equally detected in 2016, RSV-B was more frequently identified in 2017. From 318 hMPV-positive samples,

150 subgroup identification was possible for 132 specimens. Of these, $80.3 \%(106 / 132)$ were 
151 hMPV-B, which was the predominant subgroup in both years (Fig. 1B). From 1,528 samples

152 tested positive for influenza virus, there were more influenza A virus $(76.2 \%, 1,164 / 1,528)$ than

153 influenza B virus $(23.8 \%, 364 / 1,528)$. In 2016, high prevalence of influenza virus occurred

154 twice, 20.5\% (59/288) in March and 34.5\% (234/678) in September (Fig. 1C). The following

155 year, peak influenza virus activity occurred in August $(25.3 \%, 185 / 732)$. Overall, A/H3N2

156 accounted for $70 \%(815 / 1,164)$ of all influenza A virus.

157

158

159

160

161

162

163

164

165

166

167

168

169

170

171

172

\section{Genotyping and phylogenetic analysis of RSV and hMPV}

Partial G gene sequences that were randomly selected to identify the RSV genotypes showed all of the RSV-A strains (23/23) were genotype ON1 and all of the RSV-B strains (93/93) were genotype BA9 (Fig. 2A and 2B, respectively). Inter-subgroup diversity between A_ON1 and B_BA9 was relatively high (p-distance value of 2.17-2.44). In contrast, genetic variations among intra-genotype strains were relatively small ( $p$-distance value of $0-0.073$ and 0-0.071 within the ON1 and BA9 genotypes, respectively).

Partial F gene sequences were obtained from 132 of the 318 hMPV-positive specimens. Phylogenetic analysis of $132 \mathrm{hMPV}$ strains identified in this study showed two main genetic lineages, A and B. Strains clustered into subgroup A2, B1, and B2, but not subgroup A1 (Fig. 3). The majority of the strains belonged to subgroup B1 $(74 \%, 98 / 132)$, while only $6 \%(8 / 132)$ belonged to subgroup B2. The remaining 20\% of the strains (26/132) belonged to subgroup A2. The intra-genotype strains were genetically closely related (p-distance values of 0.001-0.019), while the inter-subgroup comparisons were more diverse (p-distance values of $0.087-0.116$ ). 


\section{Coinfections among RSV, hMPV, and influenza virus}

175 The frequency of single versus multiple infections and the number of co-occurrences of

176 viruses for each possible virus combination were examined (Table 4). The most common

177 combination observed was RSV(non-typed) and influenza A H3N2 subtype (n=68). As a

178 percentage, the virus most often found in coinfections was RSV, which was found in $17.4 \%$

$179(176 / 1,011)$ of the samples, followed by hMPV $(10.4 \%, 33 / 318)$, and influenza virus $(8.5 \%$, $180130 / 1,528)$ 


\section{DISCUSSION}

183

184

186

187

188

189

190

191

192

193

194

195

196

197

198

199

200

201

202

203

204

This study was conducted over a two-year study period between 2016-2017 among 8,842

patients who presented with influenza-like infections. Two multiplex real-time reverse

transcriptase polymerase chain reaction (RT-PCR) assays were used to rapidly detect three of the

most common viral respiratory pathogens. It was not surprising that influenza was the most

prevalent virus (17.3\%), followed by RSV (11.4\%) and hMPV (3.6\%). Similar to our findings,

previous study examining hospitalized patients with lower respiratory tract infections in Thailand

found that influenza viruses were the most common respiratory viruses diagnosed among ILI

cases (Chittaganpitch et al., 2018). RSV prevalence was highest among children aged $<5$ years

with rates of infection between 15.4 and $21.2 \%$. On the other hand, RSV had a lower burden of

symptomatic respiratory illness among older children and adults, and the opposite trend was

observed for influenza virus infection. The proportion of patients with influenza virus infections

increased with age, and the rate of infection was greatest in children 13-18 years of age (27.2\%).

These findings are supported by previously reported studies on the epidemiology of respiratory

virus infection (Zhang et al., 2014; Richter et al., 2016).

In the present study, the seasonal distribution of influenza virus infections resembled those of RSV and hMPV infections, which was similar to data from previous studies (Richter et al., 2016; Parsania et al., 2016; Chittaganpitch et al., 2018). Although Thailand is located geographically in the northern hemisphere, the seasonality of respiratory infection is similar to that of several nearby tropical settings such as Indonesia, Malaysia, the Philippines and the Southern hemisphere countries of Australia and New Zealand (Weber et al., 1998; Paynter et al., 2015). In these regions, respiratory infections generally peak in the rainy season and declines during the hot and dry months. Moreover, a study from Bangladesh found an increased risk of 
205

206

207

208

209

210

211

212

213

214

215

216

217

218

219

220

221

222

223

224

225

226

227

respiratory infection following rainy days, suggesting a link between rainfall and population

crowding or proximity (Murray et al., 2012). In Thailand, the period when students are in school

overlaps with the rainy season, so it is possible that host behavior is associated with an increased risk of respiratory infection.

In our study, both RSV subgroups A and B circulated during the same RSV season, but the relative proportions varied as subgroup B occurred more frequently than subgroup A in the 2017 season. Several previous studies including from our group have reported the alternating antigenic pattern of RSV infection over time (Ohno et al., 2013; Hirsh et al., 2014; Fall et al., 2016; Auksornkitti et al., 2014; Thongpan et al., 2017). It has been hypothesized that the

periodic shifts in the predominant RSV subgroup are driven by the dynamics of population immunity and subgroup-specific herd immunity (Botosso et al., 2009). Regarding the relationship between clinical severity of infection and RSV types and subtypes, some studies have observed that RSV group A infection was associated with an increased illness severity (McConnochie et al., 1990; Jafri et al., 2013), while other studies observed that RSV group B infection resulted in more severe disease (Hornsleth et al., 1998; Tran et al., 2013). In the present study, the emerging genotypes of ON1 and BA9 completely replaced the previous genotypes, such NA1, and other BA genotypes as was found in other countries (Dapat et al., 2010; Esposito et al., 2015), although it has been observed that they do not appear to cause more severe disease than other genotypes (Panayiotou et al., 2014).

Phylogenetic analysis of the hMPV F gene in the present study showed that both A and B types co-circulated in Thailand over the two-year study period. Similar to our findings, all three subtypes of hMPV (A2, B1, and B2) co-circulated each year in other studies, including South Korea, Italy, Australia, and Norway (Gerna et al., 2005; Mackay et al., 2006; Chung et al., 
228 2008; Moe et al., 2017). Although hMPV genotype A might be more virulent than genotype B

229 (Vicente et al., 2006), data in the literature on the association between clinical symptoms and

230 hMPV genotype remains unclear as some authors show a higher severity of illness, (Vicente et

231 al., 2006; Arnott et al., 2013), while others did not (Agapov et al., 2006; Manoha et al., 2007).

232 Furthermore, the prevalence of mostly influenza A H3N2 contrasts with the limited circulation of

233 influenza B during this two-year study period. The predominance of influenza A H3N2 in 2016

234 was observed both in Thailand (Suntronwong et al., 2017) and the United States (Blanton et al., 235 2017).

236 Regarding multiple infections, RSV was co-detected mainly with influenza virus

237 infection, which is consistent with an overlap of seasonal RSV and influenza virus infections.

238 There have been reports showing no relationship between disease severity and multiple virus

239 infections (Lim et al., 2016), while other studies have shown that viral co-infection was

240 significantly associated with longer duration of symptoms, especially in RSV, and that this may

241 increase the clinical severity of acute respiratory infection among children infected with RSV

242 (Cho et al., 2013; Harada et al., 2013).

243 This study had several limitations. The convenient samples in this study may not be

244 representative of the patient population in Bangkok. Since these samples were not tested for

245 other respiratory viruses such as human parainfluenza virus and rhinovirus, we may have missed

246 the identification of other respiratory pathogens. Samples were anonymized and had limited

247 accompanying clinical data, therefore we were unable to examine the association between viral

248 genotypes and clinical severity, although ILI clinical symptoms are generally similar regardless

249 of viral etiology.

250 


\section{CONCLUSION}

252 Influenza viruses were the most common respiratory viruses diagnosed among ILI cases

253 in this study. While RSV and hMPV infections were found mainly in young children and

254 sporadically in adults, influenza virus infection was prevalent in adults and the elderly. A small

255 number of individuals had dual infections, most commonly RSV and influenza A H3N2. Due to

256 overlapping seasonal occurrence of these viral infections, accurate and rapid molecular detection

257 can potentially assist clinicians and researchers in the treatment and surveillance to limit viral

258 spread. The data presented here add to our understanding of the epidemiology of RSV, hMPV,

259 and influenza causing respiratory illness in Thailand.

260

261 ACKNOWLEDGEMENTS

262 We would like to thank the staff of Bangpakok 9 International Hospital in Bangkok for

263 their technical and administrative assistance. 


\section{REFERENCES}

Agapov E, Sumino KC, Gaudreault-Keener M, Storch GA, Holtzman MJ. 2006. Genetic variability of human metapneumovirus infection: evidence of a shift in viral genotype without a change in illness. The Journal of Infectious Diseases 193(3):396-403 DOI: $10.1086 / 499310$.

Arnott A, Vong S, Sek M, Naughtin M, Beauté J, Rith S, Guillard B, Deubel V, Buchy P. 2013. Genetic variability of human metapneumovirus amongst an all ages population in Cambodia between 2007 and 2009. Infection, Genetics and Evolution 15:43-52 DOI: 10.1016/j.meegid.2011.01.016.

\section{Auksornkitti V, Kamprasert N, Thongkomplew S, Suwannakarn K, Theamboonlers A,} Samransamruajkij R, Poovorawan Y. 2014. Molecular characterization of human respiratory syncytial virus, 2010-2011: identification of genotype ON1 and a new subgroup B genotype in Thailand. Archives of Virology 159(3):499-507 DOI: 10.1007/s00705-013-1773-9.

Blanton L, Alabi N, Mustaquim D, Taylor C, Kniss K, Kramer N, Budd A, Garg S, Cummings CN, Chung J, Flannery B, Fry AM, Sessions W, Garten R, Xu X, Elal A, Gubareva L, Barnes J, Dugan V, Wentworth DE, Burns E, Katz J, Jernigan D, Brammer L. 2017. Update: Influenza Activity in the United States During the 2016-17 Season and Composition of the 2017-18 Influenza Vaccine. MMWR. Morbidity and mortality weekly report 66(25): 668-676. DOI:10.15585/mmwr.mm6625a3.

Boivin G, Abed Y, Pelletier G, Ruel L, Moisan D, Côté S, Peret TC, Erdman DD, Anderson LJ. 2002. Virological features and clinical manifestations associated with human metapneumovirus: a new paramyxovirus responsible for acute respiratory-tract 
infections in all age groups. Journal of infectious diseases 186(9):1330-1334 DOI: 10.1086/344319.

290

291

292

293

294

295

296

297

298

299

300

301

302

303

304

305

306

307

308

Boloursaz MR, Lotfian F, Aghahosseini F, Cheraghvandi A, Khalilzadeh S, Farjah A, Boloursaz M. 2013. Epidemiology of lower respiratory tract infections in children. Journal of Comprehensive Pediatrics 4(2):93-98 DOI 10.17795/compreped-10273.

Botosso VF, Zanotto PM, Ueda M, Arruda E, Gilio AE, Vieira SE, Stewien KE, Peret TC, Jamal LF, Pardini MI, Pinho JR, Massad E, Sant'anna OA, Holmes EC, Durigon EL; VGDN Consortium. 2009. Positive selection results in frequent reversible amino acid replacements in the G protein gene of human respiratory syncytial virus. PLoS Pathogen 5(1):e1000254 DOI: 10.1371/journal.ppat.1000254.

Chittaganpitch M, Waicharoen S, Yingyong T, Praphasiri P, Sangkitporn S, Olsen SJ, Lindblade KA. 2018. Viral etiologies of influenza-like illness and severe acute respiratory infections in Thailand. Influenza and Other Respiratory Viruses 12(4): 482489 DOI: 10.1111/irv.12554.

Cho HJ, Shim SY, Son DW, Sun YH, Tchah H, Jeon IS. 2013. Respiratory viruses in neonates hospitalized with acute lower respiratory tract infections. Pediatrics International 55(1):49-53 DOI: 10.1111/j.1442-200X.2012.03727.x.

Chung JY, Han TH, Kim SW, Hwang ES. 2008. Genotype variability of human metapneumovirus, South Korea. Journal of Medical Virology 80(5):902-905 DOI: 10.1002/jmv.21129.

Dapat IC, Shobugawa Y, Sano Y, Saito R, Sasaki A, Suzuki Y, Kumaki A, Zaraket H, 
Dapat C, Oguma T, Yamaguchi M, Suzuki H. 2010. New genotypes within respiratory syncytial virus group B genotype BA in Niigata, Japan. Journal of Clinical Microbiology 48(9):3423-3427 DOI: $10.1128 / \mathrm{jcm} .00646-10$.

\section{Esposito S, Piralla A, Zampiero A, Bianchini S, Di Pietro G, Scala A, Pinzani R, Fossali} E, Baldanti F, Principi N. 2015. Characteristics and their clinical relevance of respiratory syncytial virus types and genotypes circulating in Northern Italy in five consecutive winter seasons. PloS One 10(6):e0129369 DOI: 10.1371/journal.pone.0129369.

Fall A, Dia N, Cisse el HA, Kiori DE, Sarr FD, Sy S, Goudiaby D, Richard V, Niang MN. 2016. Epidemiology and Molecular Characterization of human respiratory syncytial virus in Senegal after four consecutive years of surveillance, 2012-2015. PloS One 11(6):e0157163 DOI: 10.1371/journal.pone.0157163.

Garg S, Jain S, Dawood FS, Jhung M, Pérez A, D'Mello T, Reingold A, Gershman K, Meek J, Arnold KE, Farley MM, Ryan P, Lynfield R, Morin C, Baumbach J, Hancock EB, Zansky S, Bennett N, Thomas A, Schaffner W, Finelli L. 2015. Pneumonia among adults hospitalized with laboratory-confirmed seasonal influenza virus infection-United States, 2005-2008. BMC Infectious Diseases 15:369 DOI: 10.1186/s12879-015-1004-y.

Harada Y, Kinoshita F, Yoshida LM, Minh le N, Suzuki M, Morimoto K, Toku Y, Tomimasu K, Moriuchi H, Ariyoshi K. 2013. Does respiratory virus coinfection increases the clinical severity of acute respiratory infection among children infected with respiratory syncytial virus? Pediatric Infectious Disease Journal 32(5):441-445 DOI: 10.1097/INF.0b013e31828ba08c. 
333

334

335

336

337

338

339

340

341

342

343

344

345

346

347

348

349

350

351

352

353

354

Henrickson KJ, Hoover S, Kehl KS, Hua W. 2004. National disease burden of respiratory viruses detected in children by polymerase chain reaction. Pediatric Infectious Disease Journal 23(1 Suppl):S11-18 DOI: 10.1097/01.inf.0000108188.37237.48.

\section{Hirsh S, Hindiyeh M, Kolet L, Regev L, Sherbany H, Yaary K, Mendelson E,} Mandelboim M. 2014. Epidemiological changes of respiratory syncytial virus (RSV) infections in Israel. PloS One 9(3):e90515 DOI: 10.1371/journal.pone.0090515.

Hornsleth A, Klug B, Nir M, Johansen J, Hansen KS, Christensen LS, Larsen LB. 1998. Severity of respiratory syncytial virus disease related to type and genotype of virus and to cytokine values in nasopharyngeal secretions. Pediatric Infectious Disease Journal 17(12):1114-1121.

\section{Horthongkham N, Athipanyasilp N, Sirijatuphat R, Assanasen S, Sutthent R. 2014.} Prevalence and molecular characterization of human metapneumovirus in influenza a negative sample in Thailand. Journal of Clinical Laboratory Analysis 28(5):398-404 DOI: $10.1002 /$ jcla.21700.

Jafri HS, Wu X, Makari D, Henrickson KJ. 2013. Distribution of respiratory syncytial virus subtypes A and B among infants presenting to the emergency department with lower respiratory tract infection or apnea. Pediatric Infectious Disease Journal 32(4):335-340 DOI: 10.1097/INF.0b013e318282603a.

Johnstone J, Majumdar SR, Fox JD, Marrie TJ. 2008. Human metapneumovirus pneumonia in adults: results of a prospective study. Clinical Infectious Diseases 46(4):571-574 DOI: 10.1086/526776.

Gerna G, Campanini G, Rovida F, Sarasini A, Lilleri D, Paolucci S, Marchi A, Baldanti 
F, Revello MG. 2005. Changing circulation rate of human metapneumovirus strains and types among hospitalized pediatric patients during three consecutive winter-spring seasons. Archives of Virology 150(11):2365-2375 DOI: 10.1007/s00705-005-0581-2.

Mackay IM, Bialasiewicz S, Jacob KC, McQueen E, Arden KE, Nissen MD, Sloots TP. 2006. Genetic diversity of human metapneumovirus over 4 consecutive years in Australia. The Journal of infectious diseases 193(12):1630-1633 DOI: 10.1086/504260.

Mahony JB. 2008. Detection of respiratory viruses by molecular methods. Clinical Microbiology Reviews 21(4):716-747 DOI 10.1128/CMR.00037-07.

Manoha C, Espinosa S, Aho SL, Huet F, Pothier P. 2007. Epidemiological and clinical features of hMPV, RSV and RVs infections in young children. Journal of Clinical Virology 38(3):221-226 DOI: 10.1016/j.jcv.2006.12.005.

McConnochie KM, Hall CB, Walsh EE, Roghmann KJ. 1990. Variation in severity of respiratory syncytial virus infections with subtype. Journal of Pediatrics 117:52-62.

Moe N, Krokstad S, Stenseng IH, Christensen A, Skanke LH, Risnes KR, Nordbø SA, Døllner H. 2017. Comparing human metapneumovirus and respiratory syncytial virus: viral co-detections, genotypes and risk factors for severe disease. PloS One 12(1):e0170200 DOI: 10.1371/journal.pone.0170200.

Murray EL, Klein M, Brondi L, McGowan JE, Jr., van Mels C, Brooks WA, Kleinbaum D, Goswami D, Ryan PB, Bridges CB. 2012. Rainfall, household crowding, and 
acute respiratory infections in the tropics. Epidemiology and Infection 140(1):78-86 DOI: $10.1017 / \mathrm{s} 0950268811000252$.

379

380

381

\section{Ohno A, Suzuki A, Lupisan S, Galang H, Sombrero L, Aniceto R, Okamoto M, Saito M,} Fuji N, Otomaru H, Roy CN, Yamamoto D, Tamaki R, Olveda R, Oshitani H. 2013. Genetic characterization of human respiratory syncytial virus detected in hospitalized children in the Philippines from 2008 to 2012. Journal of Clinical Virology 57(1):59-65 DOI: $10.1016 /$ j.jcv.2013.01.001.

\section{Panayiotou C, Richter J, Koliou M, Kalogirou N, Georgiou E, Christodoulou C. 2014.} Epidemiology of respiratory syncytial virus in children in Cyprus during three consecutive winter seasons (2010-2013): age distribution, seasonality and association between prevalent genotypes and disease severity. Epidemiology and Infection 142(11):2406-2411 DOI: 10.1017/s0950268814000028.

Parsania M, Poopak B, Pouriayevali MH, Haghighi S, Amirkhani A, Nateghian A. 2016. Detection of human metapneumovirus and respiratory syncytial virus by real-time polymerase chain reaction among hospitalized young children in Iran. Jundishapur Journal of Microbiology 9(3):e32974 DOI: 10.5812/jjm.32974.

Paynter S, Ware RS, Sly PD, Weinstein P, Williams G. 2015. Respiratory syncytial virus seasonality in tropical Australia. Australian and New Zealand Journal of Public Health 39(1):8-10 DOI: 10.1111/1753-6405.12347.

Richter J, Panayiotou C, Tryfonos C, Koptides D, Koliou M, Kalogirou N, Georgiou E, Christodoulou C. 2016. Aetiology of Acute Respiratory Tract Infections in Hospitalised Children in Cyprus. PloS one 11(1): e0147041. DOI: 10.1371/journal.pone.0147041.

\section{Suntronwong N, Klinfueng S, Vichiwattana P, Korkong S, Thongmee T, Vongpunsawad}


400

401

402

403

404

405

406

407

408

409

410

411

412

413

414

415

416

417

418

419

420

421

422

S, Poovorawan Y. 2017. Genetic and antigenic divergence in the influenza $A(H 3 N 2)$ virus circulating between 2016 and 2017 in Thailand. PloS One 12(12):e0189511 DOI: 10.1371/journal.pone.0189511.

Suwannakarn K, Payungporn S, Chieochansin T, Samransamruajkit R, Amonsin A, Songserm T, Chaisingh A, Chamnanpood P, Chutinimitkul S, Theamboonlers A, Poovorawan Y. 2008. Typing (A/B) and subtyping (H1/H3/H5) of influenza A viruses by multiplex real-time RT-PCR assays. Journal of Virological Methods 152(1-2):25-31 DOI: 10.1016/j.jviromet.2008.06.002.

Tamura K, Stecher G, Peterson D, Filipski A, Kumar S. 2013. MEGA6: Molecular evolutionary genetics analysis version 6.0. Molecular Biology and Evolution 30(12):2725-2729.

Thanasugarn W, Samransamruajkit R, Vanapongtipagorn P, Prapphal N, Van den Hoogen B, Osterhaus AD, Poovorawan Y. 2003. Human metapneumovirus infection in Thai children. Scandinavian Journal of Infectious Diseases 35(10):754-756.

Thongpan I, Mauleekoonphairoj J, Vichiwattana P, Korkong S, Wasitthankasem R, Vongpunsawad S, Poovorawan Y. 2017. Respiratory syncytial virus genotypes NA1, ON1, and BA9 are prevalent in Thailand, 2012-2015. PeerJ 5:e3970. DOI: 10.7717/peerj.3970.

Tran DN, Pham TM, Ha MT, Tran TT, Dang TK, Yoshida LM, Okitsu S, Hayakawa S, Mizuguchi M, Ushijima H. 2013. Molecular epidemiology and disease severity of human respiratory syncytial virus in Vietnam. PloS One 8(1):e45436 DOI: 10.1371/journal.pone.0045436.

Venter M, Madhi SA, Tiemessen CT, Schoub BD. 2001. Genetic diversity and molecular 
423

424

425

426

427

428

429

430

431

432

433

434

435

436

437

438

439

440

441

442

epidemiology of respiratory syncytial virus over four consecutive seasons in South Africa: identification of new subgroup A and B genotypes. Journal of General Virology 82(9):2117-2124.

Vicente D, Montes M, Cilla G, Perez-Yarza EG, Perez-Trallero E. 2006. Differences in clinical severity between genotype A and genotype B human metapneumovirus infection in children. Clinical Infectious Diseases 42(12):e111-3 DOI: 10.1086/504378.

Weber MW, Mulholland EK, Greenwood BM. 1998. Respiratory syncytial virus infection in tropical and developing countries. Tropical Medicine \& International Health 3(4):268-280.

Williams JV, Harris PA, Tollefson SJ, Halburnt-Rush LL, Pingsterhaus JM, Edwards KM, Wright PF, Crowe JE Jr. 2004. Human metapneumovirus and lower respiratory tract disease in otherwise healthy infants and children. New England Journal of Medicine 350(5):443-450 DOI: 10.1056/NEJMoa025472.

World Health Organization (WHO). Influenza (Seasonal). Available at http://www.who.int/mediacentre/factsheets/fs211/en. (accessed 16 April 2018)

\section{Zhang D, He Z, Xu L, Zhu X, Wu J, Wen W, Zheng Y, Deng Y, Chen J, Hu Y, Li M,} Cao K. 2014. Epidemiology characteristics of respiratory viruses found in children and adults with respiratory tract infections in southern China. International journal of infectious diseases: IJID : official publication of the International Society for Infectious Diseases 25: 159-64. DOI: 10.1016/j.ijid.2014.02.019. 


\section{Figure 1}

Seasonal distribution of infection for each virus

The monthly number of samples from patients with influenza-like illness (ILI) is shown in gray (right scale). (A) Bar graphs show RSV-positive rate with RSV-A in yellow and RSV-B in green (left scale). (B) Bar graphs show hMPV-positive rate with hMPV-A in blue and hMPV-B in red (left scale). (C) Bar graphs show frequency of influenza A (dark green) and B (light green) virus infection with $\mathrm{A} / \mathrm{H} 1 \mathrm{~N} 1$ in orange and $\mathrm{A} / \mathrm{H} 3 \mathrm{~N} 2$ in pink (left scale). 

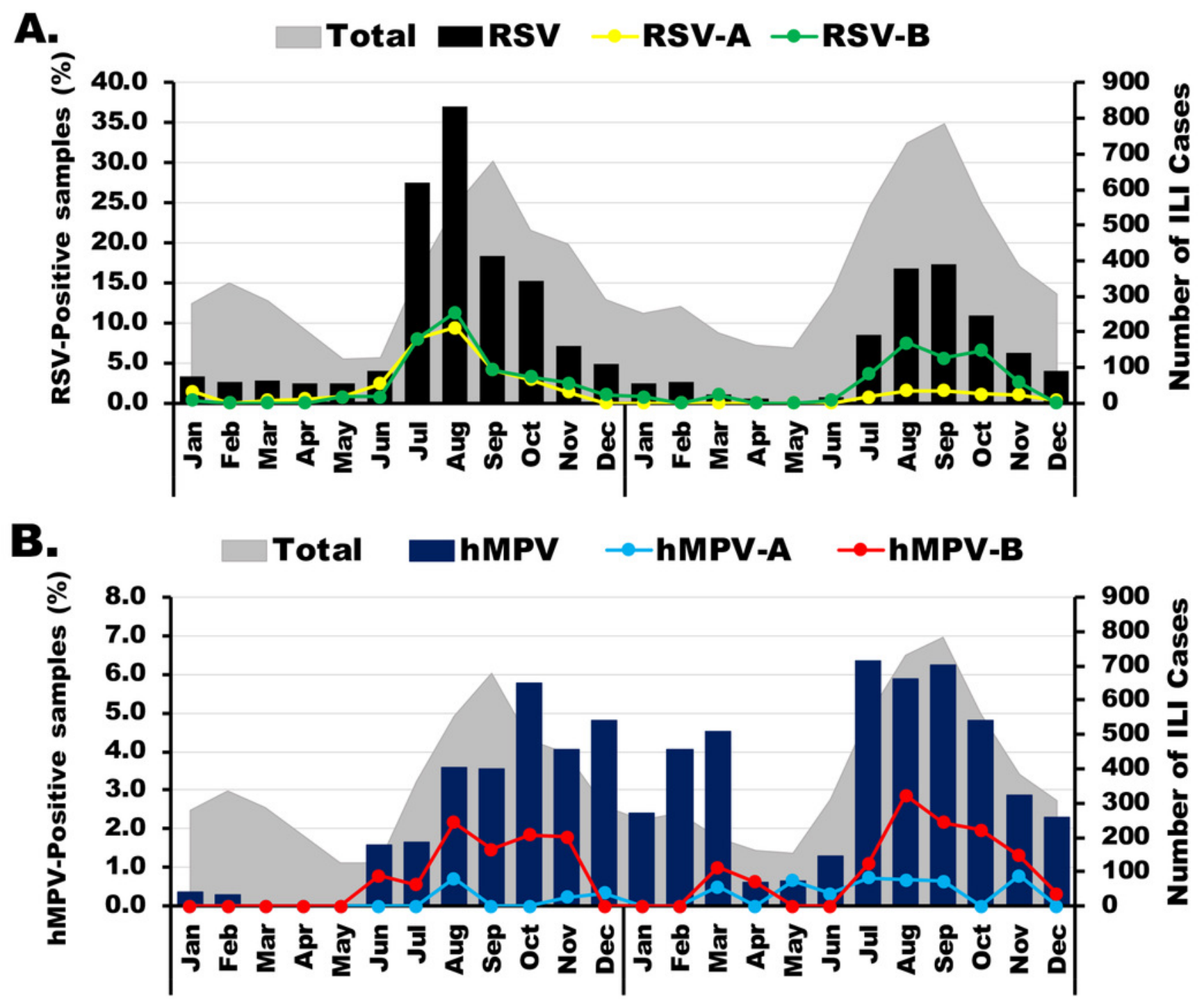

C.

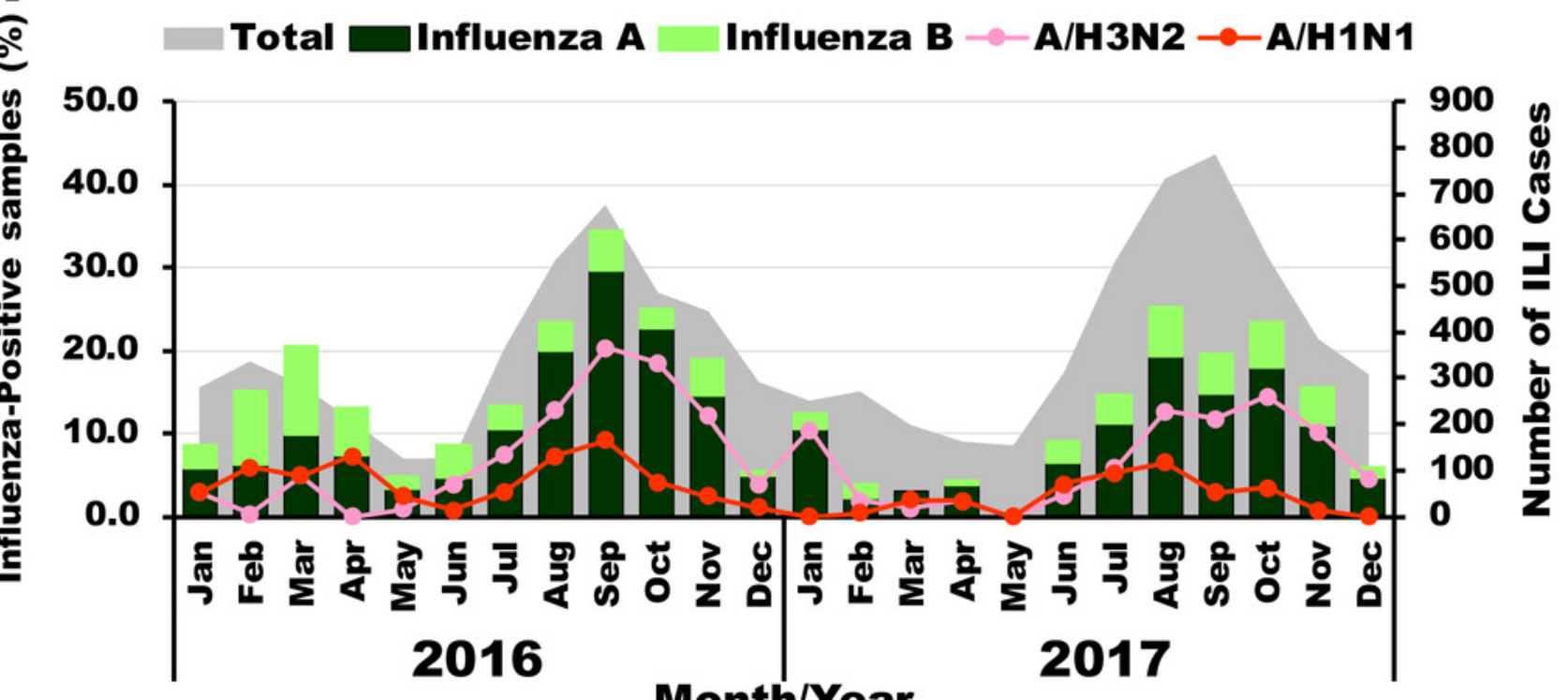




\section{Figure 2}

Phylogenetic analysis of RSV subgroup A and B based on the nucleotide sequence encompassing the HVR2 region within the $G$ gene

Trees were constructed using the maximum likelihood method based on the Tamura-Nei model and implemented in MEGA6. Bootstrap values of 1,000 pseudo-replications $>70 \%$ are indicated at the branch nodes. Reference sequences for each genotype (GA1-GA7, SAA1, NA1-NA4, and ON1 for RSV-A and GB1-GB4, SAB1-SAB4, URU1, URU2, THB, and BA1-BA10 for RSV-B) were obtained from GenBank. The scale bar represents the number of nucleotide substitutions per site between close relatives. Circles denote samples from Thailand 2016, while squares indicate strains from Thailand 2017 The number of strains are shown in parentheses. 


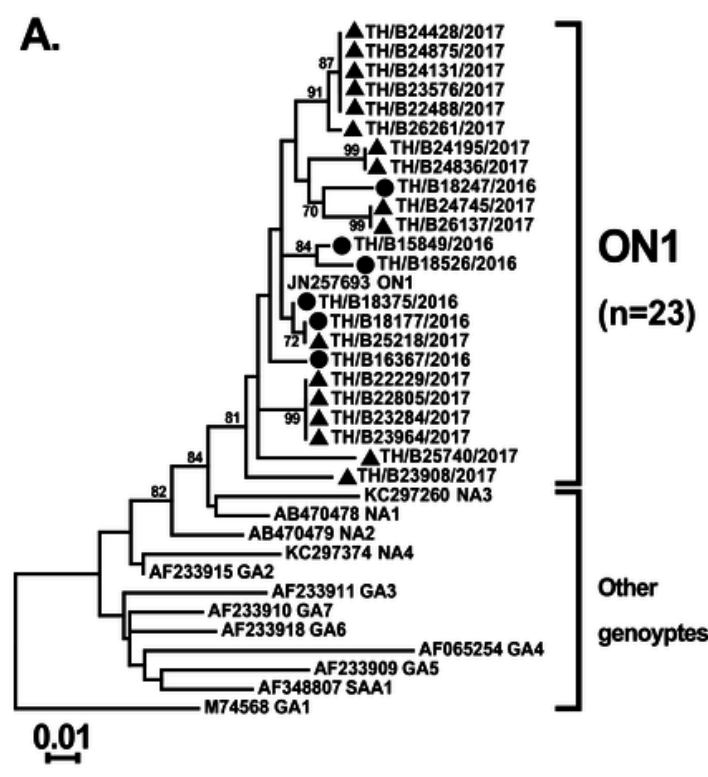

B.

BA9

$(n=93)$

Other

genotypes

AY488804 URU1

TTH/B17328/2016

NTH/B23267/2017

TH/B17528/2016

-OTH/B17372/20944/2017

OTH/B17692/2016 (1)

TH/B17496/2016

TH/B17357/2016

TH/B17060/2016 (4)

ВTH/B25357/2017

ATH/B24870/2017

1 1 TH/B23714/2017 (5)

TH/B16526/2016

84 $\triangle$ TH/B24701/2017

- АTH/B253/817042/2016

TH/B26052/2017

ATH/B24600/2017 (3)

A

- $A$ TH/B24505/2017

-

- TH/B25998/2017

-

ATH/B25643/2017

ATH/B24978/2017

ATH/B24340/2017

ATH/B25213/2017

TH/B23488/2017

-

98) TH/B17262/2016

TH/B17375/2016 (1)
TH/B17354/2016

A TH/B24790/2017

TH/B24183/2017

ATH/B24024/2017

A TH/B22488/2017 (11)

- $T H / B 22918 / 2017$

- $T$ TH/B23649/2017

- $\mathrm{A}$ TH/B25258/2017 (1)

ATH/B24299/2017 (1)

HM459878 BA9

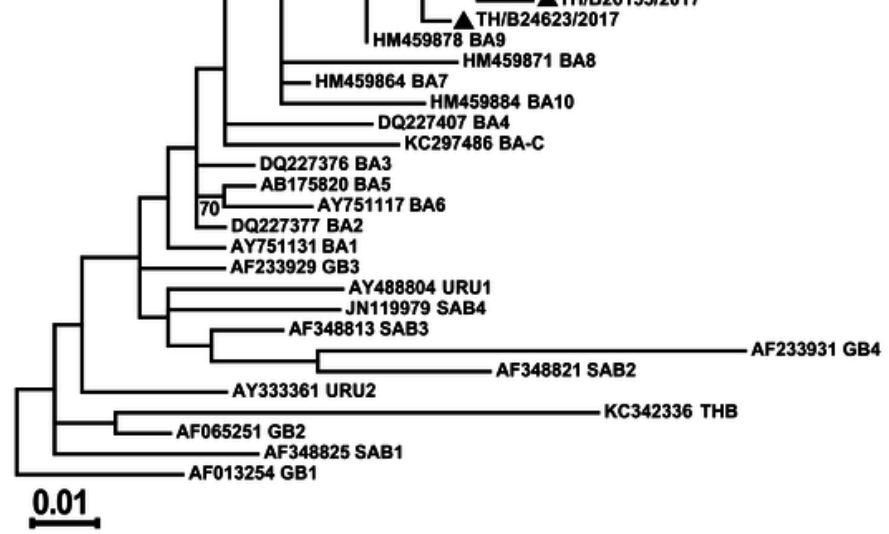




\section{Figure 3}

Phylogenetic analysis of hMPV subgroup A and B based on the partial nucleotide sequence of the $\mathrm{F}$ gene

Tree was constructed using the maximum likelihood method and the Tamura-Nei model implemented in the MEGA6. The reliability of the tree was estimated using 1000 bootstrap pseudo-replicates. Bootstrap values $>70 \%$ are indicated at the branch nodes. Reference sequences for each genotype (A1, A2, B1, and B2) were obtained from GenBank. The scale bar represents the number of nucleotide substitutions per site between close relatives.

Circles denote samples from Thailand 2016, while squares indicate strains from Thailand 2017. The number of strains are shown in parentheses. 


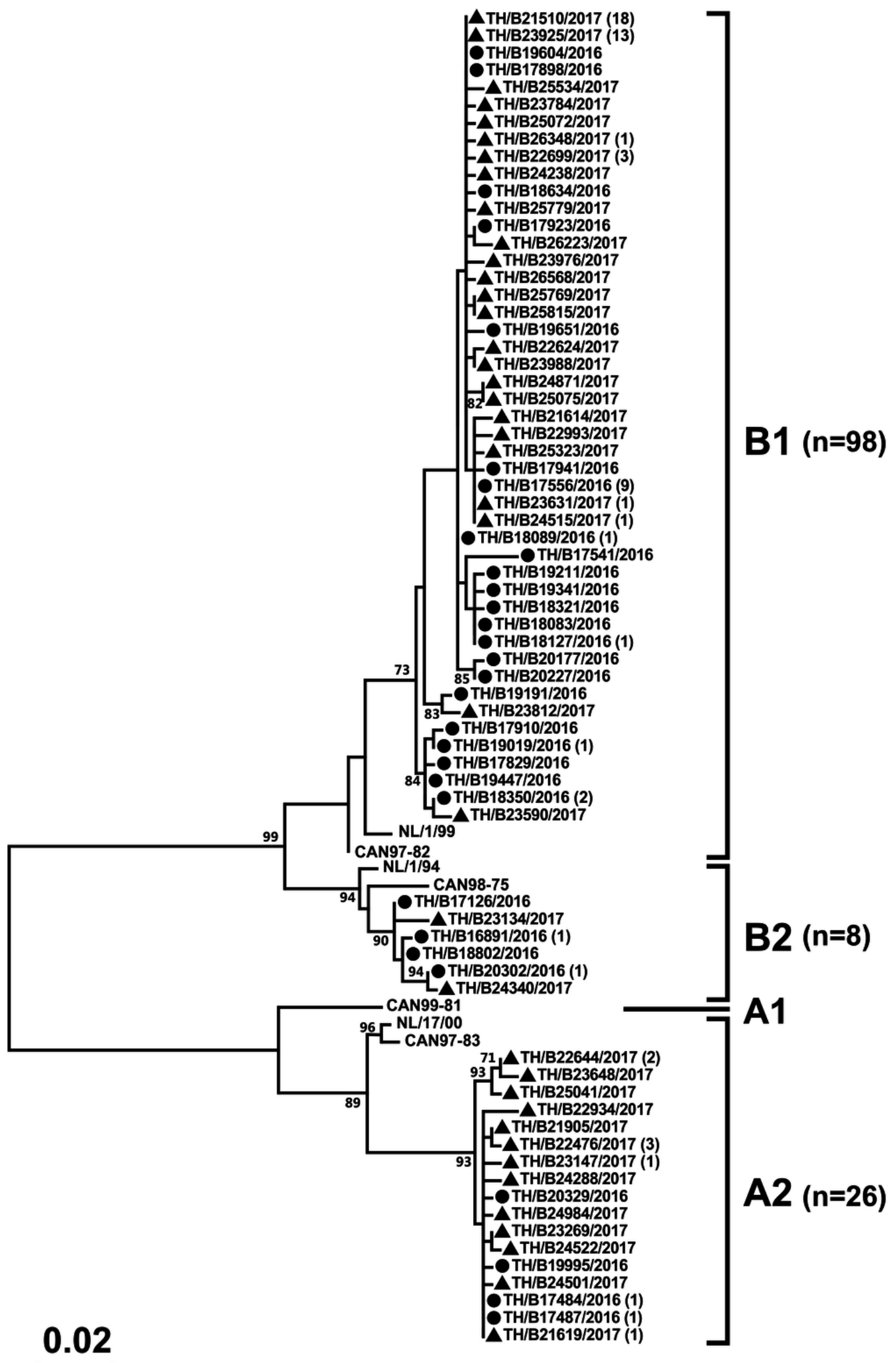




\section{Table 1 (on next page)}

Primers and probes used to detect RSV, hMPV, and influenza virus 
1 Table 1:

2 Primers and probes used to detect RSV, hMPV, and influenza virus.

\begin{tabular}{|c|c|c|c|c|c|c|}
\hline & Virus & Primer/Probe & Sequence 5'- 3' & Target & Position & \\
\hline \multirow[t]{6}{*}{ Assay 1} & RSV A and B & RSV_F3251 & GGCAAATATGGAAACATACGTGAA & $\mathrm{M}$ & $3251-3274$ & $(+)$ \\
\hline & & RSV_R3334 & TCTTTTTCTAGGACATTGTAYTGAACAG & M & $3334-3361$ & $(-)$ \\
\hline & & RSV_P3303 & FAM-CTGTGTATGTGGAGCCTTCGTGAAGCT-BHQ1 & M & $3303-3329$ & $(+)$ \\
\hline & hMPV A and B & hMPV_F3604 & CAARTGYGACATTGCTGAYCTRAA & $\mathrm{F}$ & $3604-3628$ & $(+)$ \\
\hline & & hMPV_R3683 & ACTGCCGCACAACATTTAGRAA & $\mathrm{F}$ & $3683-3662$ & $(-)$ \\
\hline & & HMPV_P3630 & JOE-TGGCYGTYAGCTTCAGTCARTTC-BHQ1 & $\mathrm{F}$ & $3630-3643$ & $(+)$ \\
\hline \multirow[t]{15}{*}{ Assay $2^{a}$} & Influenza A & FluA-M-F151 & CATGGARTGGCTAAAGACAAGACC & $\mathrm{M}$ & $151-175$ & $(+)$ \\
\hline & & FluA-M-R276 & AGGGCATTTTGGACAAAKCGTCTA & M & $276-252$ & $(-)$ \\
\hline & & FluA-M-P218 & FAM-ACGCTCACCGTGCCCAGT-BHQ1 & M & $218-235$ & $(+)$ \\
\hline & Influenza B & FluB-MF439 & CTCTGTGCTTTRTGCGARAAAC & M & $439-460$ & $(+)$ \\
\hline & & FluB-MR & ССТTCYCCATTCTTTTGACTTGC & M & $671-649$ & $(-)$ \\
\hline & & FluB-P135 & Cy5-TCAGCAATGAACACAGCAA-BHQ3 & M & $541-559$ & $(+)$ \\
\hline & Influenza $\mathrm{A} / \mathrm{H} 1 \mathrm{~N} 1$ & H1_F & ACTACTGGACTCTGCTKGAA & $\mathrm{H} 1$ & $750-769$ & $(+)$ \\
\hline & & $\mathrm{H} 1{ }^{-} \mathrm{R}$ & AAGCCTCTACTCAGTGCGAA & $\mathrm{H} 1$ & $846-827$ & $(-)$ \\
\hline & & $\mathrm{H} 1 \_\mathrm{P}$ & FAM-TTGAGGCAAATGGAAATCTAATAGC-TAMRA & $\mathrm{H} 1$ & $789-813$ & $(+)$ \\
\hline & Influenza $\mathrm{A} / \mathrm{H} 3 \mathrm{~N} 2$ & $\mathrm{H} 3{ }_{-}^{-} \mathrm{F}$ & TGCTACTGAGCTGGTTCAGAGT & $\mathrm{H} 3$ & $139-160$ & $(+)$ \\
\hline & & $\mathrm{H} 3{ }_{-}^{-} \mathrm{R}$ & AGGGTAACAGTTGCTGTRGGC & $\mathrm{H} 3$ & $322-302$ & $(-)$ \\
\hline & & H3_P & HEX-AGATGCTCTATTGGGAGACC-BHQ1 & $\mathrm{H} 3$ & $226-245$ & $(+)$ \\
\hline & GAPDH & GAPDH-F85 & GTGAAGGTCGGAGTCAACGG & GAPDH & $85-104$ & $(+)$ \\
\hline & & GAPDH-R191 & TCAATGAAGGGGTCATTGATGG & GAPDH & $191-169$ & $(-)$ \\
\hline & & GAPDH-P121 & HEX-CGCCTGGTCACCAGGGCTGC-BHQ1 & GAPDH & $121-140$ & $(+)$ \\
\hline
\end{tabular}

3 a Previously described in Suwannakarn et al., 2008.

$4 \quad(+)$ and (-) denote sense and anti-sense strand, respectively.

5

6 
Table 2 (on next page)

Overall prevalence of samples tested positive for RSV, hMPV or influenza virus. 
1 Table 2:

2 Overall prevalence of samples tested positive for RSV, hMPV or influenza virus.

3

\begin{tabular}{llllll}
\hline Year & $\begin{array}{l}\text { No. of } \\
\text { samples }\end{array}$ & $\begin{array}{l}\text { Virus-positive } \\
\text { samples (\%) }\end{array}$ & $\begin{array}{l}\text { RSV-positive } \\
(\%)\end{array}$ & $\begin{array}{l}\text { hMPV- } \\
\text { positive (\%) }\end{array}$ & $\begin{array}{l}\text { Influenza } \\
\text { virus-positive } \\
(\%)\end{array}$ \\
\hline $\mathbf{2 0 1 6}$ & 4,178 & $1,428(34.2)$ & $590(14.1)$ & $114(2.7)$ & $814(19.5)$ \\
$\mathbf{2 0 1 7}$ & 4,664 & $1,271(27.3)$ & $421(9.0)$ & $204(4.4)$ & $714(15.3)$ \\
Total & 8,842 & $2,699(30.5)$ & $1,011(11.4)$ & $318(3.6)$ & $1,528(17.3)$ \\
\hline
\end{tabular}

4 


\section{Table 3 (on next page)}

Characteristics of samples and detection frequency of RSV, hMPV, and influenza virus. 


\section{Table 3:}

2 Characteristics of samples and detection frequency of RSV, $h M P V$, and influenza virus.

\begin{tabular}{|c|c|c|c|c|c|}
\hline Characteristics & & $\begin{array}{l}\text { Samples } \\
(\%) \\
(\mathrm{N}=8,842) \\
\end{array}$ & $\begin{array}{l}\text { RSV } \\
(\%) \\
(\mathrm{N}=1,011)\end{array}$ & $\begin{array}{l}\text { hMPV } \\
(\%) \\
(\mathrm{N}=318) \\
\end{array}$ & $\begin{array}{l}\text { Influenza } A+B \\
(\%) \\
(N=1,528)\end{array}$ \\
\hline \multirow{14}{*}{$\begin{array}{l}\text { Age, year } \\
(\text { mean } \pm \text { SD age })\end{array}$} & $\leq 2$ & $1,916(21.7)$ & $406(21.2)$ & $105(5.5)$ & $134(7.0)$ \\
\hline & $(1.2 \pm 0.6)$ & & & & \\
\hline & $3-5$ & $1,541(17.4)$ & $238(15.4)$ & $88(5.7)$ & $160(10.4)$ \\
\hline & $(3.8 \pm 0.8)$ & & & & \\
\hline & $6-12$ & $1,253(14.2)$ & $100(8.0)$ & $25(2.0)$ & $298(23.8)$ \\
\hline & $(8.4 \pm 1.9)$ & & & & \\
\hline & $13-18$ & $371(4.2)$ & $19(5.1)$ & $10(2.7)$ & $101(27.2)$ \\
\hline & $(15.2 \pm 3.2)$ & & & & \\
\hline & $19-30$ & $1,148(13.0)$ & $66(5.7)$ & $20(1.7)$ & $211(18.4)$ \\
\hline & $(25.4 \pm 3.2)$ & & & & \\
\hline & $31-60$ & $2,164(24.5)$ & $144(6.7)$ & $53(2.4)$ & $516(23.9)$ \\
\hline & $(41.4 \pm 8.1)$ & & & & \\
\hline & $>60$ & $449(5.1)$ & $38(8.5)$ & $17(3.8)$ & $108(24.1)$ \\
\hline & $(72.0 \pm 9.1)$ & & & & \\
\hline p-value & & & 0.0262 & 0.5695 & $<0.0001$ \\
\hline Gender & Male & $4,288(48.5)$ & $514(50.8)$ & $160(50.3)$ & 742 (48.6) \\
\hline
\end{tabular}

3 Statistically significant differences among groups are bolded. 
Table 4 (on next page)

Contribution of respiratory viruses as single or coinfections. 
1 Table 4. Contribution of respiratory viruses as single or coinfections.

\begin{tabular}{|c|c|c|c|c|c|c|c|c|c|c|c|c|c|c|c|}
\hline$\stackrel{\mathscr{E}}{=}$ & 吾 & 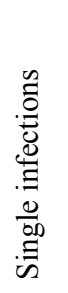 & $\begin{array}{l}\mathscr{0} \\
. \stackrel{0}{0} \\
\stackrel{0}{0} \\
. \Xi \\
\stackrel{0}{0} \\
\stackrel{0}{0} \\
\stackrel{0}{0}\end{array}$ & 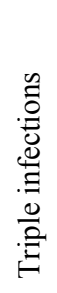 & 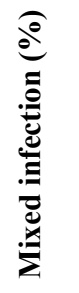 & 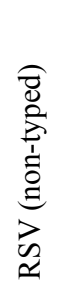 & $\begin{array}{l}\ll \\
21 \\
2 \\
2\end{array}$ & $\begin{array}{l}n \\
n_{0}^{1} \\
\approx\end{array}$ & 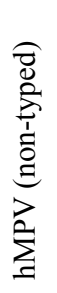 & $\begin{array}{l}\sum_{1}^{2} \\
\sum_{j}^{1} \\
\sum^{2}\end{array}$ & 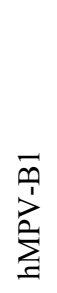 & 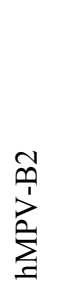 & 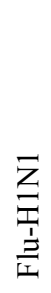 & $\underset{\substack{Z\\
}}{\stackrel{\Xi}{\Xi}}$ & $\frac{m}{\frac{1}{I}}$ \\
\hline RSV (non-typed) & 527 & 397 & 128 & 2 & 25.0 & - & 0 & 0 & 18 & 1 & 1 & 1 & 23 & 68 & 20 \\
\hline RSV-A & 176 & 158 & 18 & 0 & 10.2 & 0 & - & 13 & 1 & 0 & 1 & 0 & 1 & 2 & 0 \\
\hline RSV-B & 321 & 293 & 27 & 1 & 8.7 & 0 & 13 & - & 3 & 1 & 1 & 0 & 2 & 6 & 3 \\
\hline hMPV (non-typed) & 186 & 161 & 22 & 3 & 13.4 & 18 & 1 & 3 & - & 0 & 0 & 0 & 1 & 3 & 2 \\
\hline hMPV-A2 & 26 & 24 & 2 & 0 & 7.7 & 1 & 0 & 1 & 0 & - & 0 & 0 & 0 & 0 & 0 \\
\hline hMPV-B1 & 98 & 93 & 5 & 0 & 5.1 & 1 & 1 & 1 & 0 & 0 & - & 0 & 1 & 0 & 1 \\
\hline hMPV-B2 & 8 & 7 & 1 & 0 & 12.5 & 1 & 0 & 0 & 0 & 0 & 0 & - & 0 & 0 & 0 \\
\hline Flu-H1N1 & 349 & 321 & 28 & 0 & 8.0 & 23 & 1 & 2 & 1 & 0 & 1 & 0 & - & 0 & 0 \\
\hline Flu-H3N2 & 815 & 738 & 75 & 2 & 9.4 & 68 & 2 & 6 & 3 & 0 & 0 & 0 & 0 & - & 0 \\
\hline Flu-B & 364 & 338 & 24 & 1 & 6.9 & 20 & 0 & 3 & 2 & 0 & 1 & 0 & 0 & 0 & - \\
\hline
\end{tabular}

